\title{
Construction of Social Governance System for the Plight Children from the Perspective of Socialization of Children's Welfare
}

\author{
Shuyan Li, Ying Quan \\ Preschool Education and Special Education College, Kunming University, Kunming 650214,China
}

Keywords: the plight children; socialization of children's welfare; child protection

\begin{abstract}
With the continuous progress and development of our society, the theory of social governance provides a new perspective for the construction of the social governance system for the plight children. This paper analyzes and studies the problems existing in the process of constructing the social governance system for the plight children, some countermeasures such as establishing the state guardianship system, defining the responsibilities of each department and enhancing the credibility of the building of the children's welfare homes are provided in this paper, which provide certain reference value for the relevant departments to formulate measures to protect the plight of children.
\end{abstract}

\section{Introduction}

At present, China's plight of children's social governance system is still in exploration practice, there are many imperfections in the governance system. In our country, some protection laws and regulations of children is not comprehensive and specific, the protection system of children's lack of social policy and service support, lack of strong organizational guarantee, so our country for the protection of children need to establish a sound system of social governance.

\section{Socialization of children's welfare}

The meaning of social welfare. The primary objective of social welfare is to promote the social and economic needs of every member of society. The social welfare intention enables people of different ages in the society to promote the functioning of social functions. Especially when other systems in society, such as the market economy and the family, do not meet the basic needs of the people, then social welfare is more needed to serve them. Social welfare is a system in which the state or society provides free or preferential prices to some citizens or all citizens in accordance with the law and the corresponding social policies. In terms of its functions, the development of social welfare can help alleviate the citizen income distribution adjustment, the first time in the field of distribution contradiction, improve social welfare, in order to let more citizens share the fruits of economic development, and promote the coordinated development of social stability.

Social welfare and children welfare. Children's welfare is one of the important parts of social welfare. It is the embodiment of social welfare in the special group of children. In 1959, the United Nations Declaration on the Rights of the Child pointed out: "all efforts to promote the healthy development of children's physical and mental and normal life for the purpose of all kinds of efforts, undertakings and systems, etc., are called" child welfare." The narrow sense of child welfare means that the appointed institution provides special services to the special children. The object of service mainly refers to the children who are in trouble, and the main functions of the service are relief, assistance, etc. it is a kind of negative welfare for children. Children's welfare in the broad sense, it serves not only the children in distress, but all the children in society, is a positive child welfare. The basic structure of children's welfare in distress is shown in Figure 1. 


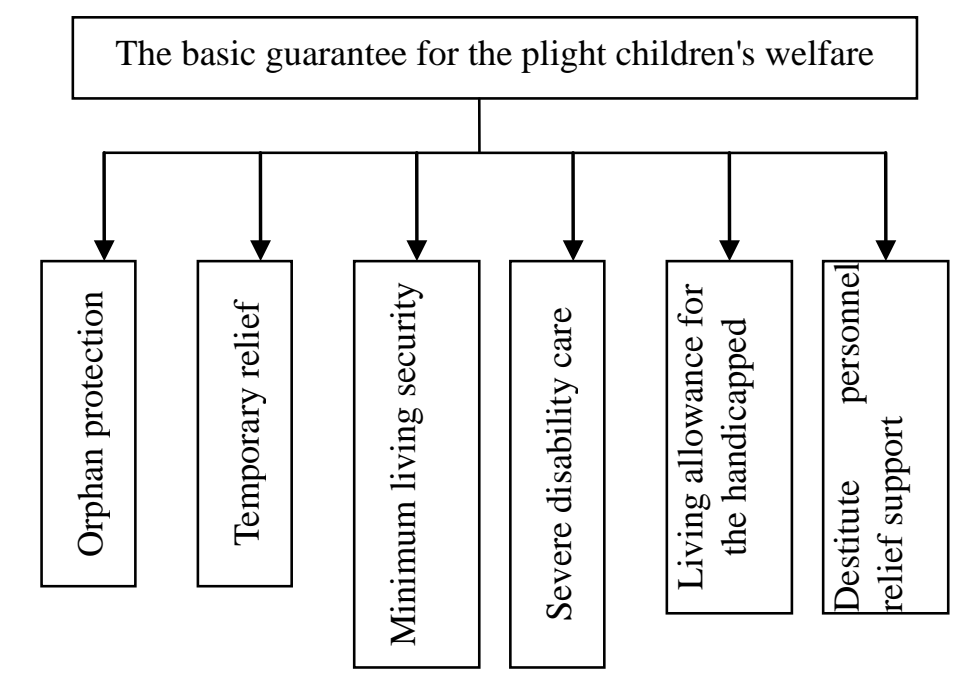

Fig.1 Basic guarantee structure diagram of plight children's welfare

Concept of the plight children. There is no unified definition for the concept of the plight children. Scholar Wang Qi believes that children in plight refer to minors who have temporarily or permanently lost custody of their parents. Wu Guoping believes that the plight of children refers to minors under 14 years of age, and parents are dead or unattended, including orphans, abandoned babies, and practically unattended children. Shang Xiaoyuan believes that the definition of the plight of children can be divided into three level concept, the first concept is the plight of children; the second concept is the plight of physical children, the social plight children and multiple plight children; the third concept is the physiological plight of children, including disabled children and children with serious illnesses, socially plight children include two two-level concepts, namely, children who are separated from their families and children in difficult situations.

\section{The problems existing in the social construction system of the plight children at present}

There are no perfect laws and regulations. In 1991, in order to protect minors, China promulgated the first special law and regulations for the protection of minors, called the law on the protection of minors. It was modified in People's Republic of China in 2006 Tenth National People's Congress Standing Committee of the twenty-fifth meeting, but still only the protection system of the children made provisions in principle, clause and no detailed description of the specific relationship. We can see some provisions for the punishment of child abuse behavior, in the constitution, civil law, criminal law, law on the protection of minors, the marriage law and other legal documents at present but these legal documents the terms are too rough, the lack of specific penalties. From this we can see that although there are many laws and regulations about the protection of children, they are only scattered in the provisions of various legal documents and lack certain deterrent power. At the same time for child protection legislation analysis, mostly according to the law to say, lack of perfect laws and regulations, and not to set up laws and regulations from the perspective of children, children really need to understand what protective measures.

The setup of organ is unreasonable. From the perspective of children's welfare system in china, the Department concerned with children are: The Coordination Committee of the State Council, the work of children Finance Bureau, Civil Affairs Bureau, development and Reform Commission, the Education Bureau, Health Bureau, labor bureau, bureau of justice and other government administrative departments, as well as the Communist Youth League, women's federations, federations and other mass organizations, but China is still not established a specialized administrative agencies in order to protect the children. Of course, these departments are involved in child protection work, but due to the different departments have different policies for the protection of children, because they may overlap or are missing in the execution of the work in the protection of children. The fundamental reason is that these administrative bodies have not been effectively linked, there is no clear division of labor for the protection of children, the lack of 
administrative departments and coordination of these departments.

The work capacity of community neighborhood committees is limited. The community refers to the neighborhood committees, the residents committees or the villagers committees, which are the most grass-roots mass autonomous organizations in China. Their main function is to coordinate the interests between the government and the members of the community. At the same time, they play a role in publicizing state laws and regulations and educating residents to fulfill their obligations conscientiously. They need to know the families of the residents in a timely manner and master the latest developments in the family, so they can also understand the children's information for the first time. Although the neighborhood committees do not solve the administrative rights of some things, they are indeed the effective departments of government failure and play an important role. They are also a major part of the work of protecting children. But for some parents in the community who do not perform their duties as guardian children, the neighborhood committees can only contact these parents, educate and advise them, and can not take other coercive measures. This is mainly because neighborhood committees are limited by their own responsibilities and don't know what they can do to protect children in trouble.

\section{Construction of social governance system for the plight children}

The plight of children's social governance system construction from three aspects: starting from the national level, the establishment of national guardianship system can be effective; starting from the grassroots level departments and agencies, to clarify the responsibilities of various departments; starting from the social level, strengthen the construction of children's welfare trust. The structure of the system is shown in Figure 2.

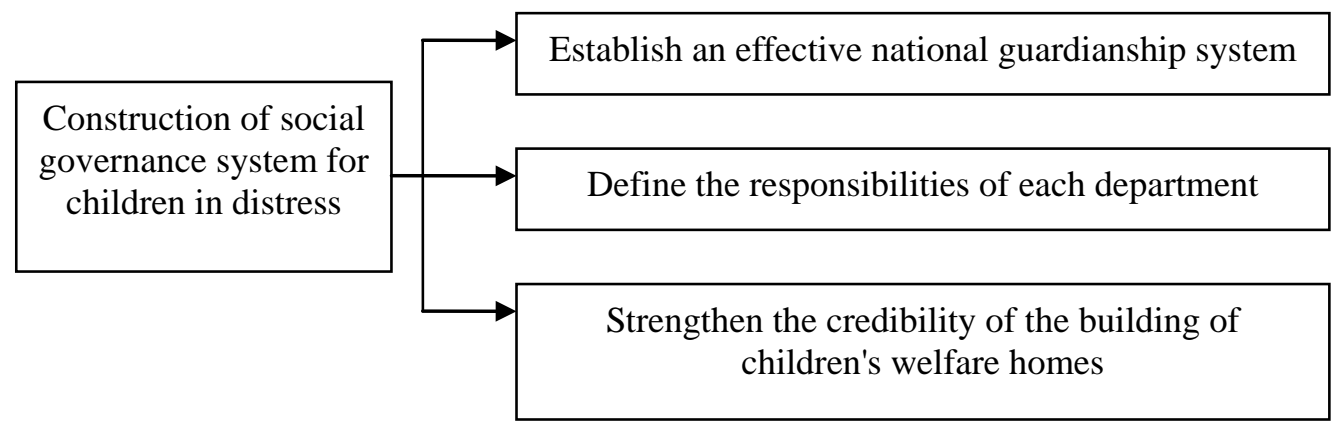

Fig.2 The structure of social governance system for the plight children

Establish an effective national guardianship system. When children in difficult circumstances lack the supervision of their parents, the state should take the initiative to intervene and take temporary or long-term responsibility for the maintenance or guardianship of children in distress. The establishment of the national monitoring system, in the "civil law" in the provisions, when minors' guardian does not fulfill the responsibility of guardianship or infringe the legitimate rights and interests of the guardian, government agencies have the right to apply to the people's court to disqualify a guardian. At present, the number of children in our country is very large. We can only define the state as the guardian of children in distress. When the country as their guardian, in the implementation of the work, should establish and perfect a series of national monitoring system and the corresponding measures for the monitoring of the subject, object, scope, procedures and contents of responsibility so as to make clear, have dedicated staff to strengthen the security of funds and intensify supervision, so that children get really effective protection.

Define the responsibilities of each department. The system is based on effective carrying capacity and binding force. In order to implement the system, only through the implementation of procedures and procedures, otherwise the system can only become an armchair system. At present, many of our policies are difficult to implement, largely because of the specific work procedures and the main responsibility is not clear. Therefore, the protection system to implement the plight of children effectively, in system design to protect the plight of children, you should specify the 
various agencies should assume what responsibility for children, what they should do, what should not be done, and the violation should bear the duties should bear what responsibility. We should establish a mechanism for the internal affairs of the Ministry of civil affairs and inter departmental cooperation, clear the division of responsibilities among departments, and realize the seamless connection. For departments that are difficult to differentiate between duties, joint meetings and referral mechanisms are needed to help solve the problem.

Strengthen the credibility of the building of children's welfare homes. In order to effectively improve the service quality of the welfare homes for the plight children, we should strengthen the credibility of the building of children's welfare homes. First of all, the need to focus on strengthening mechanism of their credibility construction, improve the internal system response ask responsibility; secondly, to explore mechanisms for the plight of children in welfare institutions responsible; third welfare also must face the society with a more open attitude, so that the formation of the whole society to supervise the government attention to the plight of children's consciousness gradually; finally. Is responsible for the government, welfare as a Civil Affairs Bureau subordinate institutions, lack of autonomy, which led to the government accountability is too strong, other stakeholders accountability is too weak or lack of risk, the need to constantly deepen and gradually improve China's political system.

\section{Conclusion}

The system for the protection of the plight of children has been conducted reform and improvement for many times in our country, which can be said to have been recognized by the community, but there are still some problems in the process of practice, so the analysis of these problems, how to improve the protection system of the plight of children is very important, need the government and all sectors of society to give concern and attention. This article puts forward some measures for the establishment of social governance system for children in distress, hoping that they can really help and serve the children in distress.

\section{Acknowledgments}

The work was supported by two projects. One is from the Youth Project of National Social Science Foundation with item number 13CSH014.The one is from Natural Science Foundation of China with the Grant No. 71361023.

\section{Reference}

[1] Wu Pengfei, Liu Jinjing. The construction of China's Child allowance system under an appropriate universal-typesocial welfare mode [J]. Social Security Studies, No.02, (2016), p. 91-96.

[2] Xing Hongfang. Analysis of the construction way of the plight of children classified security system [J]. Academic Journal of Zhongzhou, No. 08, (2016) , p.62-67.

[3] Kang Guilan. The government behavior studies of appropriate universal-typesocial child welfare system construction in Quanzhou city [D]. Huaqiao University, (2016).

[4] Yu Fei. Study on the current situation and construction path of children's welfare system in China [D]. Hebei Normal University, (2015).

[5] Zhang Ziqi, Xu Jiawen. Disabled children at home and abroad relief system comparative analysis of [J]. Science and Technology Innovation Herald, Vol. 23, (2015) , p.231-232.

[6] Gao Liru, Peng Huamin. Study on the plight of children Chinese trajectory: concepts, policies and theme [J]. Jianghai Academic Journal, No. 04, (2015) , p.111-117, 239. 
[7] Liu Kewen, Chen Tianzhu. Review and Inspiration of the concept of child welfare [J]. People's Tribune, No.11, (2015) , p.167-169.

[8] Wei Jiaqi. China's child welfare policy on the development of [J]. Legal System and Society, Vol.20, (2014), p.166-167.

[9] Tian Ye. Study on improving the welfare system of children in China [D]. Hebei University, (2014).

[10] Sun Tiantian. Development of Linyi children's Welfare Institute from the perspective of socialization of children's welfare [D]. Nanjing Normal University, (2013).

[11] Wang Wei. Intervention study of social work on children's institutional parenting model [D]. South-Central University For Nationalities, (2013).

[12] Cheng Haijun. The transformation and evolution of China's children's welfare system [J]. Social Welfare, No.09, (2012), p.24-30.

[13] Wu Xue. Research on China's child welfare policy framework [D]. Nanjing University of Technology, (2012).

[14] Jiang Xiuna. Socialization of child welfare from the perspective of orphans and disabled children in foster care model to explore the [J]. Social Welfare, No. 03, (2012) , p.22-26.

[15] Jiang Xia. Study on public expenditure of preschool education in China from the perspective of child welfare [D]. Nanjing Normal University, (2011).

[16] Guo Hongliang. Child welfare model and its development from the group of disabled children [D]. Southwestern University of Finance and Economics, (2010). 